Best Pract Res Clin Haematol. 2011 June ; 24(2): 203-216. doi:10.1016/j.beha.2011.02.009.

\title{
Rituximab Resistance
}

\author{
Andrew R. Rezvani, MD and David G. Maloney, MD, PhD \\ Fred Hutchinson Cancer Research Center and University of Washington, Seattle, WA, USA
}

Andrew R. Rezvani: arezvani@fhcrc.org; David G. Maloney: dmaloney@fhcrc.org

\section{Abstract}

Rituximab has become a ubiquitous component of treatment regimens for follicular non-Hodgkin lymphoma. Despite widespread clinical use, the mechanisms by which tumor cells resist rituximab-mediated destruction remain unclear. Rituximab relies in part on immune effector mechanisms for its antitumor effect, and thus resistance may be mediated not only by intrinsic tumor-cell alterations but also by the host immunological environment. In this article, we explore the mechanisms of action of rituximab, the incidence of rituximab resistance, and potential mechanisms of resistance. Finally, we discuss novel approaches to modulate the antibody, the tumor cell, and the host immunologic environment to overcome rituximab resistance. Further research into the mechanisms of rituximab resistance will be essential to improving the efficacy of anti-CD20 therapy in NHL, and may also pay dividends in the optimization of monoclonal antibody therapy across a wide range of diseases.

\section{Keywords}

Lymphoma; Follicular; Antibodies; Monoclonal; Drug Resistance; Neoplasm; Pharmacokinetics

\section{INTRODUCTION}

The anti-CD20 monoclonal antibody rituximab has emerged as a vital component of therapy for follicular non-Hodgkin lymphoma (NHL). Rituximab is routinely incorporated into all phases of conventional treatment, including first-line therapy, maintenance, and salvage therapy, and it has been used investigationally in hematopoietic cell transplantation (HCT) for follicular NHL [1-3]. Thus, rituximab can justifiably be described as the most effective, successful, and widely used therapeutic monoclonal antibody developed to date.

Nonetheless, as with any antineoplastic agent, the effectiveness of rituximab is ultimately limited in part by the development of treatment resistance. With conventional chemotherapeutic agents, numerous pathways of tumor resistance have been elucidated. In some cases, this knowledge has translated into specific interventions aimed at preventing or

(C) 2011 Elsevier Ltd. All rights reserved.

Correspondence to: Andrew R. Rezvani, arezvani@fhcrc.org.

Andrew R. Rezvani, MD, 1100 Fairview Ave N, D1-100, Seattle, WA 98109 USA, Phone: (206) 667-1505, Fax: (206) 667-6124

David G. Maloney, MD, PhD, Phone: (206) 667-5616, Fax: (206) 667-6124

Conflict of interest statement

Andrew R. Rezvani: No conflicts of interest.

David G. Maloney: honorarium, F. Hoffman La Roche; honorarium, Spectrum Pharmaceuticals

Publisher's Disclaimer: This is a PDF file of an unedited manuscript that has been accepted for publication. As a service to our customers we are providing this early version of the manuscript. The manuscript will undergo copyediting, typesetting, and review of the resulting proof before it is published in its final citable form. Please note that during the production process errors may be discovered which could affect the content, and all legal disclaimers that apply to the journal pertain. 
overcoming tumor resistance. Surprisingly, relatively little is known about the determinants of responsiveness and resistance to rituximab in the treatment of B-cell NHL. The precise mechanism of action of rituximab in the patient-either as a single agent or in combination with chemotherapy-remains subject to considerable uncertainty, which further complicates discussion of the mechanisms of resistance. Rituximab resistance is likely not mediated purely by tumor-specific alterations. Because rituximab depends in part on activation of the host immune system to kill tumor cells, host factors also play a significant role in rituximab effectiveness and resistance.

Nonetheless, existing clinical and basic investigations provide some insight into the incidence, impact, and mechanisms of rituximab resistance. The topic is an important one not only because of the widespread use of rituximab, but also because insights into rituximab resistance may be relevant to other members of the rapidly proliferating class of antitumor antibodies. Additionally, such insights could enable the rational design of future monoclonal antibodies with the goal of limiting or circumventing tumor resistance. Finally, given the financial and logistical costs associated with prolonged courses of monoclonal antibody therapy, a means of identifying patients truly resistant to rituximab might avoid the costs of unnecessary treatment both for the individual patient and for the medical system.

In this chapter, we will review current knowledge on the mechanism of action of rituximab, the incidence of rituximab resistance, potential mechanisms of resistance, approaches to predict rituximab resistance, and implications of rituximab resistance for future investigations.

\section{RITUXIMAB: MECHANISMS OF ACTION}

Rituximab is a chimeric mouse-human monoclonal antibody consisting of a human kappa constant region, a human $\mathrm{IgG} 1 \mathrm{Fc}$ portion, and a murine variable region which recognizes human CD20 [4]. The CD20 molecule is expressed across most of the committed stages of normal B-cell development, from pre-B cell to mature, activated, and memory B cells, as well as by virtually all B-cell malignancies. Some T-lymphocyte subsets, both benign and malignant, have also been reported to express low levels of CD20 [5,6], although the clinical significance of this finding appears negligible. CD20 is lost when B cells terminally differentiate into plasma cells. Thus, CD20 provides a B-cell-specific target which spares both hematopoietic stem cells and antibody-producing plasma cells. This antigenic distribution makes CD20 an appealing target for therapeutic antibodies in NHL. Additionally, CD20 is highly expressed on the cell surface and is not rapidly internalized after antibody binding $[7,8]$. The biological function of CD20 is unclear, although some evidence suggests a role in $\mathrm{Ca}^{2+}$ ion influx and homeostasis [9]. CD20 has no known natural ligand, and mice deficient in CD20 have a nearly normal phenotype [10].

Once rituximab binds to $\mathrm{CD} 20$, the antibody-antigen complex translocates to lipid rafts within the cell membrane [11]. Lipid rafts (membrane domains rich in cholesterol and sphingolipids) serve as a setting for signal transduction by localizing both effectors and receptors. Lipid rafts are heterogeneous and highly dynamic [12], which has hampered research into their characteristics. However, it is increasingly recognized that variations in lipid raft composition may play an important role in rituximab resistance. Malignant B cells have been shown to produce aberrant lipid rafts [13], and at least one study has associated the glycosphingolipid content of lipid rafts in NHL cells with sensitivity to rituximab treatment [14].

Binding of rituximab to CD20 results in the depletion of both normal and malignant B cells. Unlike radioisotope- or immunotoxin-conjugated monoclonal antibodies, rituximab carries no effector "payload". Its effects are mediated solely through antibody-antigen interactions 
with CD20 and through subsequent interactions with components of the immune system. At least 4 major mechanistic pathways have been proposed by which rituximab causes B-cell depletion. All of these pathways are likely active in the clinical setting, but their relative contributions to the clinical effect of rituximab remain unclear. These mechanisms include:

\section{a. Complement-dependent cytotoxicity}

The complement system may be triggered by the binding of the serum protein $\mathrm{C} 1 \mathrm{q}$ to the $\mathrm{Fc}$ portion of IgG antibodies such as rituximab. Once triggered, the complement system consists of a signaling cascade, which ultimately may generate a membrane attack complex which disrupts the cell membranes of antibody-bound cells. Separately, components of the activated complement system may act as opsonins by binding complement receptors on phagocytes and NK cells.

Complement-dependent cytotoxicity (CDC) has been demonstrated as an aspect of rituximab activity in vitro $[15,16]$. Evidence for the in vivo role of CDC is less clear. In some murine models of lymphoma, rituximab was effective in destroying CD20-expressing tumors despite the depletion of NK cells, neutrophils, or both, and in nude athymic mice. On the other hand, rituximab was entirely ineffective in knockout mice lacking C1q (and, thus, complement activity) [17]. These results suggest that CDC alone, in the absence of cellular effector mechanisms, is necessary and sufficient to mediate the therapeutic effects of rituximab. However, another group found that rituximab effectively depleted normal B cells in a mouse model deficient for $\mathrm{C} 3, \mathrm{C} 4$, and $\mathrm{C} 1 \mathrm{q}$, and concluded that complement activity was unnecessary and that rituximab's action was more dependent on Fc-receptor-mediated cellular mechanisms [18].

In humans with chronic lymphocytic leukemia (CLL), rituximab infusion results in rapid and profound depletion of complement components [19], suggesting that complement depletion may be a factor in rituximab treatment failure. Genetic polymorphisms in the gene for $\mathrm{C} 1 \mathrm{q}$ have been linked to variations in rituximab efficacy in humans, again supporting a key role for CDC in rituximab efficacy [20]. CLL cells surviving rituximab therapy express high levels of complement regulatory proteins, which inhibit the cytotoxic action of complement [21]. On the other hand, tumor expression of complement inhibitors does not correlate with rituximab sensitivity or resistance in follicular NHL [22], suggesting that CDC may not be essential for rituximab efficacy in NHL. Nonetheless, several avenues of research aim to overcome rituximab resistance by modulating the complement system, underscoring the relevance of this pathway to anti-CD20 antibody development.

Interestingly, complement activation may be responsible for some infusion-related side effects which commonly occur with the first dose of rituximab. While these adverse reactions are often ascribed to "cytokine release", the actual evidence implicating specific cytokines is limited. In contrast, van der Kolk and others made a convincing case for complement activation, rather than cytokine release, as the precipitating factor in adverse reactions to rituximab infusion [23]. Thus, the complement-activating characteristics of rituximab may be a double-edged sword, with important implications for efforts to augment this mechanism.

\section{b. Antibody-dependent cellular cytotoxicity}

Antibody-dependent cellular cytotoxicity (ADCC) is an arm of the immune response initiated by antigen-bound antibody and effected by cells bearing the Fc $\gamma$ receptor (e.g. NK cells, granulocytes, macrophages). These cells recognize antigen-bound rituximab via their Fc receptors and lyse the antibody-bound cells through their respective effector mechanisms. The induction of ADCC by rituximab has been demonstrated in vitro [16]. Murine models 
have supported an in vivo role for ADCC. For example, Uchida et al. showed that the depletion of normal murine B cells by anti-CD20 antibody was dependent on Fc $\gamma$ RI and RIII, and that B-cell depletion did not occur in FckR-deficient mice [18].

In humans, ADCC seems to be an important mediator of rituximab efficacy. Some supporting data come from studies of single nucleotide polymorphisms (SNP) in FCGR3A (Table 1). In humans, a SNP in FCGR3A can result in the substitution of either a valine (V) or phenylalanine $(\mathrm{F})$ residue at position 158 of the FCkRIIIa receptor. Cells bearing Fc receptor homozygous for $\mathrm{V}(158 \mathrm{~V} / \mathrm{V})$ have a higher in vitro affinity for IgG1 compared to cells with $158 \mathrm{~V} / \mathrm{F}$ or $158 \mathrm{~F} / \mathrm{F}$ receptor [24]. The clinical relevance of this polymorphism has been demonstrated in a series of studies showing higher response rates to rituximab in NHL patients with the $158 \mathrm{~V} / \mathrm{V}$ receptor, as compared to patients with $158 \mathrm{~V} / \mathrm{F}$ or $158 \mathrm{~F} / \mathrm{F}$ receptor [25-27]. Importantly, these polymorphisms have no prognostic significance in patients followed expectantly or treated with chemotherapy alone [28]; their impact is limited to patients receiving rituximab, suggesting a prominent role of ADCC as an effector mechanism for anti-CD20 therapy. In contrast to the literature on NHL, the FCGR3A genotype did not have any impact on outcomes in B-cell CLL treated with rituximab [29], suggesting that the clinical contribution of ADCC may depend on the characteristics of the underlying malignant cells.

\section{c. Induction of apoptosis}

A third proposed mechanism of action of rituximab is the induction of apoptosis. This pathway is more complex than CDC and ADCC, and correspondingly less is known about its specifics. The binding of rituximab to $\mathrm{CD} 20$ has been shown to induce apoptosis in several B cell lines [30-32], although it is less effective against fresh malignant B cells. Presumably, apoptosis activation is also significant in vivo, although it is difficult to demonstrate experimentally. While some groups have suggested that caspase activation is central to the induction of apoptosis by rituximab [33], others have reported caspaseindependent apoptosis [34,35]. Similarly, the literature is conflicting on the question of whether caspase inhibitors prevent rituximab-induced apoptosis [34-36]. The role of caspase is of clinical interest because most cytotoxic chemotherapeutic agents mediate apoptosis via caspase-dependent pathways, and the modulation of these pathways is a major mechanism of chemotherapy resistance. Thus, if rituximab does not depend on caspase-mediated apoptosis, it may evade one of the most common mechanisms of tumor cross-resistance. A second apoptotic pathway of interest is mediated by proteins from the bcl-2 gene family. This gene family includes both pro- and anti-apoptotic proteins, and cellular susceptibility to apoptosis is mediated in part by the balance between conflicting signals from these proteins. Overexpression of bcl-2 is common in B-cell NHL and predicts aggressive disease, chemotherapy resistance, and a poorer prognosis [37]. Interestingly, rituximab (when added to cytotoxic chemotherapy) appears capable of overcoming this resistance [38].

Some of the discrepancy in reported findings on rituximab-induced apoptosis likely reflects variance in the specific cell lines and model systems used. Follicular NHL in humans likely contains a non-uniform mix of cells, and it has been suggested that tumor cell subsets may vary in their susceptibility to rituximab-induced apoptosis. As has been proposed in other malignancies, there may be a subset of follicular NHL "stem cells" which are resistant to rituximab-induced apoptosis, and which may contribute to the inevitable relapse of follicular NHL after chemoimmunotherapy. However, at this point, evidence in support of this speculation is lacking. 


\section{d. "Vaccination" and cross-priming}

Following rituximab-induced apoptosis of NHL cells, as described above, it has been suggested that rituximab can facilitate the uptake and cross-presentation of lymphomaspecific antigens by antigen-presenting cells (APC). Selenko et al. have proposed that apoptotic cells (as opposed to those lysed by complement or ADCC) produce debris which is taken up by APC and cross-presented (that is, cellular proteins are presented to effector cells in conjunction with MHC Class I, rather Class II) [39]. This cross-presentation leads to the expansion of cytotoxic T lymphocytes (CTL) specific for lymphoma-associated antigens, producing a "vaccination" effect. Cross-priming facilitated by rituximab has been demonstrated in vitro, using Daudi lymphoma cells [40]. The in vivo occurrence and clinical significance of rituximab-mediated cross-priming remains speculative. However, if this pathway is active, it may be particularly relevant in the setting of allogeneic hematopoietic cell transplantation, where cross-priming might generate donor lymphoma-specific CTL and contribute to the immunologic graft-vs.-lymphoma effect.

\section{INCIDENCE OF RITUXIMAB RESISTANCE}

The incidence of rituximab resistance is difficult to determine, and may vary depending on the definition and degree of resistance. In current practice, rituximab is typically combined with cytotoxic chemotherapy. Thus, the contribution of rituximab to the efficacy of a given regimen is unknown. The generally accepted definition of rituximab resistance is a lack of response to a rituximab-containing regimen, or progression within 6 months of treatment with a rituximab-containing regimen. Overt disease progression during rituximab therapy is the most clearly defined form of resistance. Patients who experience tumor shrinkage likely have some degree of rituximab sensitivity, but may nonetheless be classified as "resistant" if they fail to achieve classical criteria for partial or complete response.

Data from early studies of single-agent rituximab help elucidate the baseline incidence of rituximab resistance in antibody-naïve patients. In early Phase II studies using rituximab as a single agent in patients with relapsed indolent NHL, the overall response rate by intent-totreat analysis was 46\% [41], although subsequent single-agent trials have reported higher response rates $(67 \%)$ in chemotherapy-naïve patients [42]. In patients with bulky indolent NHL (largest node $\geq 10 \mathrm{~cm}$ ), the response rate to single-agent rituximab (43\%) was not appreciably different from that seen in non-bulky disease [43]. When patients relapsing after an initial response to rituximab were re-treated, an overall response rate of $40 \%$ was reported using strict response criteria, although $73 \%$ of patients had tumor shrinkage of at least 20\% [44]. Summarizing these data, one might conclude that approximately 30-60\% of antibody-naïve indolent NHL patients are "resistant" to rituximab at baseline. However, several important caveats should be considered. The reported response rates are based on tumor-shrinkage criteria developed for cytotoxic chemotherapy, which may not be an ideal predictor of the success of antibody therapy. In addition, several mechanisms of synergy between rituximab and cytotoxic chemotherapy have been proposed, suggesting that the true rate of rituximab resistance may be lower when the antibody is combined with other agents (as is current standard practice). In patients relapsing after a course of single-agent rituximab, approximately $60 \%$ will fail to achieve a partial or complete response with a second course of single-agent rituximab. In randomized clinical trials, the addition of rituximab to CVP chemotherapy for indolent NHL improves overall and complete response rates by $20-30 \%$, providing one measure of the differential impact of rituximab [45].

Additional data come from long-term maintenance therapy. Patients treated initially with single-agent rituximab clearly benefit from repeated courses of maintenance rituximab [42], as do patients treated with upfront chemotherapy [46]. However, the applicability of these results is limited, since virtually all patients with follicular NHL now receive combination 
chemoimmunotherapy as first-line treatment in current practice. Preliminary results from the PRIMA trial, a randomized study of maintenance rituximab in patients treated with upfront chemoimmunotherapy, show a higher rate of progression-free survival with 2 years of maintenance rituximab, as well as a 50\% reduction in relative risk of NHL relapse [47]. Taken together, these results suggest that prolonged courses of rituximab are effective in patients with follicular NHL. Thus, for an appreciable number of patients, rituximab resistance does not develop despite up to 2 years of ongoing antibody treatment.

Similar indirect clinical evidence comes from studies incorporating rituximab as maintenance therapy after high-dose chemotherapy and autologous hematopoietic cell transplantation (HCT). In patients undergoing autologous HCT for aggressive B-cell NHL, case-control studies suggest a benefit to maintenance rituximab after transplantation despite heavy prior antibody exposure [1]. Long-term maintenance has also been reported to eradicate PCR-detectable minimal residual disease after autologous HCT, again despite heavy prior exposure to rituximab [2]. While these results do not directly address the incidence or timeline of rituximab resistance, they do ndicate that many patients retain meaningful rituximab sensitivity despite numerous rounds of antibody treatment. On the basis of these data, and given the favorable side-effect profile of rituximab, the antibody is usually incorporated into successive treatment regimens regardless of tumor response or progression with previous rituximab-containing regimens. Nonetheless, additional studies formally evaluating the role of continued rituximab in combination with salvage chemotherapy regimens for NHL are needed.

\section{MECHANISMS OF RITUXIMAB RESISTANCE}

The exact mechanisms of rituximab resistance remain poorly understood. Potential mechanisms of tumor resistance have been described in each of the three major pathways of proposed rituximab action (complement fixation, ADCC, and apoptosis induction). Host immunologic factors, such as Fc receptor polymorphisms, have also been implicated. More general mechanisms include alterations in rituximab pharmacokinetics, suggesting that dose and schedule may contribute to rituximab resistance. Frank loss of CD20 expression, either through downregulation or through "shaving" of rituximab/CD20 complexes, and antigenic modulation (previously thought to be of little importance to rituximab) has recently been reconsidered as a mechanism of resistance [48]. The exact contribution of these mechanisms to the clinical phenomenon of rituximab resistance is difficult to evaluate.

\section{a. Resistance to complement-dependent cytotoxicity}

Since CDC is thought to play a role in the action of rituximab, the complement pathway has been one focus of research into rituximab resistance. Tumor cells are capable of blocking the activation of complement through the action of membrane complement regulatory proteins (mCRP) such as CD46, CD55, and CD59. These inhibitory proteins, which disrupt the complement cascade or the assembly of the membrane attack complex, are widely expressed in virtually all types of cancer and may confer protection against CDC [49]. Some rituximab-resistant cell lines have been reported to express high levels of mCRP [50], possibly as a consequence of selective pressure from repeated exposure to rituximab. If mCRP are neutralized with blocking antibodies, the efficacy of rituximab is greatly augmented in preclinical models [51]. However, mCRP serve an important regulatory role in protecting normal cells from runaway complement-mediated cytotoxicity, which may restrict the clinical application of mCRP blockade. At present, there are no clinical agents capable of specifically block cancer-associated mCRP while retaining mCRP protection of normal cells, although this is an ongoing focus of research interest [52-54]. Interestingly, the synergy between rituximab and fludarabine is thought to mediated at least partly by the 
ability of fludarabine to downmodulate CD55, thus increasing the susceptibility of cells to rituximab-mediated CDC [55].

Rituximab exposure may exhaust the store of complement proteins. Thus, rituximab "resistance" might be mediated in part by the depletion of the necessary effector molecules. This idea has been explored by Klepfish et al., who infused rituximab-resistant CLL patients with fresh frozen plasma (replete with abundant complement proteins) in conjunction with rituximab doses. This approach resulted in a "rapid and dramatic clinical response in all patients", lending support to the hypothesis that complement depletion plays a clinically significant role in rituximab resistance [56]. In 2010, a group from Nanjing, China reported similarly positive results by combining fresh frozen plasma with rituximab to overcome complement depletion and rituximab resistance in CLL patients [57]. However, as these results are preliminary and uncontrolled, further investigation is necessary to substantiate a role for complement repletion in overcoming rituximab resistance. Additionally, rituximabinduced CDC may play a smaller role in follicular NHL, where disease is primarily nodal, as opposed to CLL, where the disease is predominantly marrow- and peripheral-blood-based.

\section{b. Resistance to antibody-dependent cellular cytotoxicity}

While ADCC is thought to be a major mechanism underlying the effectiveness of rituximab, less is known about specific pathways by which tumor cells resist ADCC. Recognition of bound antibody by effector cells (NK cells, macrophages, etc.) may depend on conformational changes in the CD20/rituximab complex which occur in the cell membrane. For example, exposure to statins, which inhibit cholesterol synthesis, impaired rituximabmediated ADCC in vitro [58], suggesting that alterations to the lipid raft might lead to ADCC resistance. The best-described influence on rituximab-mediated ADCC appears to be the host FCGR3A genotype. As noted above, polymorphisms in this Fc receptor affect the affinity of effector cells for rituximab Fc. This effect appears clinically relevant; as noted above, NHL patients with a low affinity (158F/F) Fc $\gamma$ RIIIa have lower rates of response and progression-free survival when treated with rituximab.

Interestingly, serum complement activation may impair ADCC. C3b, a complement protein, may inhibit NK-driven ADCC. C3 depletion restores ADCC activity in an in vitro model, and improves the survival of mice treated with rituximab in a syngeneic murine lymphoma model [59]. Thus, complement depletion may actually augment rituximab efficacy by improving the efficiency of ADCC.

\section{c. Resistance to apoptosis}

The direct binding of rituximab to CD20 may trigger low-level apoptosis of tumor cells. Thus, alterations in apoptotic pathway signaling could lead cells to become resistant to rituximab. Rituximab-resistant cell lines have been generated through repeated exposure to antibody. These cell lines demonstrate apoptosis resistance and lack sensitivity to multiple cytotoxic chemotherapeutic agents as well as rituximab. Jazirehi et al. have described numerous modulations of pro- and anti-apoptotic regulators in these rituximab-resistant cell lines [60]. Specifically, the nuclear factor-kappaB (NFKB) pathway is hyperactivated, leading to overexpression of antiapoptotic proteins from the Bcl-2 family. These clones can be resensitized to rituximab by exposing them to inhibitors of these survival pathways in vitro [60].

The bcl-2 gene family has been a focus of investigation into rituximab resistance. The Bcl-2 protein is overexpressed in B-cell NHL and conveys resistance to apoptosis and chemotherapy. Brief exposure to rituximab may inhibit Bcl-2 expression, thus sensitizing cells to apoptosis and cytotoxic chemotherapy [61]. However, Czuczman et al. reported that 
prolonged rituximab exposure led to downregulation of the pro-apoptotic Bcl-2 family proteins Bax and Bak. These cell lines were resistant to multiple antineoplastic agents, presumably because low expression of Bax and Bak rendered the cells apoptosis-resistant. This hypothesis was supported by demonstrating that the add-back of exogenous wild-type Bax and Bak resensitized these cell lines to rituximab-mediated apoptosis [62]. These data suggest that modulation of Bax and Bak may be key mechanisms by which NHL cells develop resistance to rituximab-mediated apoptosis.

\section{d. Downregulation, modulation, mutation, or loss of CD20}

One of the most obvious mechanisms of rituximab resistance is loss of CD20, the target antigen. Until recently, however, data supporting such a mechanism were sparse, and initially consisted only of case reports of CD20-negative NHL relapses in patients who had previously expressed the antigen [63]. The incidence of complete CD20 loss after rituximab therapy seems low. However, several groups have identified more subtle changes in CD20 expression which may be linked to rituximab resistance. Some rituximab-resistant cell lines show decreased expression of CD20 at both the pre- and post-translation levels. This decreased CD20 expression led to changes in lipid raft organization and downstream signaling, suggesting that the impact of CD20 expression on rituximab resistance is more complex than simple antibody-antigen ratios [64]. Antigenic modulation of CD20 was long postulated as a possible resistance mechanism, but has been demonstrated only recently. Beers et al. described internalization of CD20 by CLL and mantle cell lymphoma cells exposed to rituximab, although follicular NHL was relatively resistant to CD20 internalization, perhaps explaining its greater clinical responsiveness to rituximab [48]. Separately, the first reports of acquired CD20 mutations were published in 2009. Terui et al. identified C-terminal deletion mutations of the CD20 gene in a subset of tumor samples from patients with NHL [65]. These mutations decreased the mean fluorescent intensity of CD20, presumably affecting antibody binding and playing a role in rituximab resistance.

A separate mechanism for CD20 loss in rituximab-resistant malignancies has been called "shaving". Beum et al. showed that rituximab/CD20 complexes can be removed from the Bcell surface by monocytes through the Fc receptor pathway [66]. That is, the antibody/CD20 complexes were "shaved" from the cell surface (rather than being internalized), resulting in antigen loss and rituximab resistance. The same group demonstrated that intravenous immune globulin (IVIG) could block the shaving reaction, confirming that it is Fc-receptormediated [67]. Thus, recognition of antigen-bound rituximab by Fc-bearing cells can trigger either shaving (leading to rituximab resistance) or ADCC (leading to rituximab efficacy). The effector cell type may determine which of the two reactions occurs. Shaving appears to be mediated by monocytes, whereas ADCC occurs when the antigen/antibody complex is recognized by NK cells [68]. Thus, rituximab efficacy might theoretically be enhanced by augmenting NK cell function while inhibiting monocyte function, thus favoring ADCC over shaving.

\section{e. Tumor microenvironment}

The tumor microenvironment is currently thought to play a significant role in cancer biology, and likely contributes to the effectiveness of rituximab. The dominant mechanism of rituximab-induced B-cell depletion appears to vary depending on the microenvironment. Gong et al. showed that in a human-CD20 transgenic mouse model, circulating B cells were depleted through ADCC, while B cells in the marginal zone of lymph nodes were lysed primarily by CDC [69]. B cells in the germinal centers of lymph nodes receive additional survival signals which may render them more resistant to rituximab. Clinically, B cells appear to be easily depleted from the blood by rituximab, while bone marrow and lymph node sites are slower and more difficult to clear. As always, the role of the 
microenvironment is difficult to assess, given the heterogeneity of factors involved and the limitations of current knowledge of normal and aberrant microenvironmental interactions. It is certainly plausible that signals from the microenvironment play a role in rituximab resistance, perhaps explaining in part the differences in response rates among various CD20expressing malignancies, but at present our knowledge of this aspect of antibody resistance is extremely limited.

\section{f. Dosing considerations}

Surprisingly, there has been little effort to guide rituximab dose and schedule. The dosing regimens commonly used in clinical practice were derived as much from early logistical and production-related factors as from pharmacokinetic data. Early studies of single-agent rituximab showed higher serum concentrations of antibody in responding patients, and lower levels in non-responding patients. However, no studies have addressed the question of whether a non-responding patient with low serum rituximab levels can be converted to a responder by modulating rituximab dose or schedule. Clinical trials driven specifically by pharmacokinetic sampling are needed to assess this aspect of rituximab resistance.

Some groups have encouraged the use of higher doses of rituximab (e.g. $1000 \mathrm{mg} / \mathrm{m}^{2} /$ dose) [70], although data favoring this or any other dosing regimen are limited. The pharmacokinetics of rituximab are known to be highly variable, and are likely affected by patient factors, disease type (NHL vs. CLL), and disease burden. Significant dose-response relationships to rituximab have been described in murine models of NHL [71], although such a relationship has not been definitively demonstrated in humans. In the absence of hard data, pharmacokinetic simulations of varying rituximab doses in follicular NHL have been proposed, for example by Ternant et al. [72], although these simulations remain to be validated with clinical data. In summary, rituximab pharmacokinetics may play a role in rituximab resistance. However, this hypothesis remains to be supported with clinical trial data aimed at targeting rituximab serum levels in resistant patients.

\section{APPROACHES TO CIRCUMVENT RITUXIMAB RESISTANCE}

A number of approaches have been explored to enhance the effectiveness of antibody therapy. Insights into rituximab resistance have also been applied to the molecular design of novel anti-lymphoma monoclonal antibodies. It remains to be determined whether these next-generation antibodies will have greater clinical activity than rituximab.

\section{a. Improving rituximab efficacy}

Enhancing CD20 antigen expression may improve antibody-mediated killing. It has been postulated that epigenetic changes are at least partly responsible for decreases in CD20 expression [73]. Drawing on this hypothesis, Shimizu et al. showed that the histone deacetylase (HDAC) inhibitors valproic acid and romidepsin increased CD20 expression and enhanced the cytotoxic effect of rituximab, primarily through the complementdependent pathway [74]. At present, in vivo data are lacking.

Alterations in pro- and anti-apoptotic regulatory proteins may also impact rituximab sensitivity and resistance. Thus, some investigation has focused on increasing the sensitivity of tumor cells to rituximab-induced apoptosis by modulating intracellular signal transduction pathways. Both pathway-specific and non-pathway-specific proapoptotic agents have been studied. Temsirolimus, bortezomib, and HDAC inhibitors have been shown in vitro to sensitize lymphoma cells to rituximab [74-76], and bortezomib has entered clinical tials in combination with rituximab as a salvage treatment for B-cell NHL [77]. Interestingly, at least one in vitro model has shown that bortezomib can mediate a decrease in CD20 expression, thus potentially inhibiting the effect of rituximab, but the 
clinical significance of this finding is unknown [78]. Since anti-apoptotic members of the Bcl-2 protein family have been implicated in rituximab resistance, there has been interest in Bcl-2 inhibitors such as the antisense nucleotide oblimersen. A Phase II study combining oblimersen with rituximab reported promising results, with a response rate of $60 \%$ in follicular NHL patients (including some with rituximab-refractory disease) [79]. Ideally, these findings will be further tested in larger randomized trials involving rituximab-resistant patients.

Enhancement of ADCC has been studied as a means to improve rituximab efficacy and overcome resistance. Several cytokines have been investigated as adjuncts to rituximab to boost ADCC. The growth factors G-CSF and GM-CSF increased the expression of neutrophil adhesion molecules and synergistically augmented the effectiveness of rituximab in NHL-bearing immunodeficient mice [80]. In clinical trials, G-CSF combined with rituximab produced a response rate of $42 \%$ in patients with indolent NHL [81]. While this response rate was not appreciably different from that seen with rituximab alone, there was a suggestion of prolonged duration of response with G-CSF. Other cytokines that have been combined with rituximab to enhance ADCC include interferon-gamma, IL-2, and IL-15 [8284]. Of these, IL-2 augmentation is perhaps the best-studied. A phase II trial in patients with rituximab-resistant indolent NHL found that IL-2 enhanced biological indicators of ADCC, but did not produce clinical responses (overall response rate 9\%) [83]. Newer approaches to augmenting rituximab-induced ADCC have included the use of $\mathrm{CpG}$ oligonucleotides, bromohydrin pyrophosphate (a nonpeptide phosphoantigen), and Toll-like-receptor 9 (TLR-9) agonists [85-87].

Depletion of complement proteins may contribute to rituximab resistance. Several groups have investigated the infusion of fresh frozen plasma to replete complement levels as a means of overcoming rituximab resistance in CLL [56,57]. Results are interesting, but remain to be confirmed in controlled trials. Since CDC seems to play a smaller role in follicular NHL as compared to CLL, this approach maybe less useful for follicular NHL. Rituximab dosing is a largely unexplored approach to overcoming rituximab resistance. It is unknown whether rituximab-resistant patients might respond to higher doses of the antibody. A lack of knowledge of threshold serum concentrations necessary for effectiveness, as well as the lack of a commercially available serum assay to quantify rituximab levels, have hampered investigation along these lines. Pharmacokinetic-driven clinical trials are needed to clarify the role of rituximab dose and schedule.

\section{b. Novel anti-CD20 antibodies}

Insights into mechanisms of rituximab resistance have informed the development of novel anti-CD20 monoclonal antibodies, some of which have entered advanced-phase clinical trials in humans. Anti-CD20 antibodies have been divided into Type I and Type II, based on epitopes and binding effects. Most anti-CD20 molecules described in the literature are Type I antibodies, which stabilize CD20 in lipid rafts and induce CDC, but only weakly induce apoptosis in vitro. Examples of this class include rituximab itself, ofatumumab, veltuzumab, and ocrelizumab. In contrast, Type II antibodies do not localize CD20 into lipid rafts and only weakly induce CDC, but appear to induce higher levels of apoptosis. The most widely studied type II anti-CD20 antibodies are tositumomab and the novel glycoengineered antibody GA-101.

Ofatumumab is a fully humanized monoclonal antibody which binds to a novel epitope on CD20. Ofatumumab has greater avidity for CD20 and a slower dissociation rate, which may enhance CDC. Ofatumumab induces translocation of CD20 into lipid rafts, similarly to rituximab, and leads to $\mathrm{CDC}$ and $\mathrm{ADCC}$ but does not trigger apoptosis [88]. In vitro, ofatumumab produces more potent $\mathrm{CDC}$ than rituximab, and appears to be more resistant to 
the effect of complement-regulatory proteins [89]. Some groups have reported equivalent ADCC to rituximab, while others have reported that ofatumumab induces more potent ADCC [90]. In Phase I/II clinical trials of ofatumumab in patients with follicular NHL reported an overall response rate of $64 \%$ in patients previously treated with rituximab, including responses in 3 of 4 patients deemed rituximab-resistant by the authors [91]. However, a subsequent study focused specifically on patients with rituximab-resistant follicular NHL found a response rate of $22 \%$ in patients resistant to single-agent rituximab and only $9 \%$ in patients resistant to rituximab/chemotherapy combinations [92]. Preliminary reports in patients with CLL suggest that ofatumumab is effective regardless of prior rituximab exposure [93], although ofatumumab has not been studied specifically in CLL patients with rituximab-refractory disease.

Several other type I anti-CD20 antibodies have been studied. Ocrelizumab is a chimeric IgG1 anti-CD20 monoclonal antibody which binds a different (but overlapping) epitope than rituximab. Ocrelizumab shows substantially greater ADCC activity and less CDC activity as compared to rituximab. The decrease in complement activation may translate into fewer infusion-related side effects, as these adverse reactions are thought to be complementmediated. Ocrelizumab has been studied clinically in rheumatoid arthritis (in combination with methotrexate) [94]. In patients with follicular NHL and previous rituximab exposure (though not necessarily rituximab resistance), single-agent ocrelizumab produced a $38 \%$ overall response rate with a very low incidence of serious infusion-related adverse events [95].

Veltuzumab is a chimeric IgG1 anti-CD20 monoclonal antibody. Its complementaritydetermining region (CDR) differs from rituximab in only a single amino acid in $\mathrm{CDR}_{3}-\mathrm{V}_{\mathrm{H}}$. This minor structural difference translates into a slower dissociation rate as compared to rituximab [96]. Veltuzumab has also been reported to produce more potent CDC in some in vitro models, and greater antitumor efficacy in animal models as compared to rituximab. In early-phase clinical trials, the overall response rate to single-agent veltuzumab was $44 \%$ in patients with follicular NHL and prior rituximab exposure [97].

Several other type I anti-CD20 monoclonal antibodies have been produced and are being tested in ongoing phase I/II clinical trials. These include molecules such as AME-133 and PRO13192I, in which the Fc portion of the antibody has been modified to enhance its affinity for Fc $\gamma$ RIIIa and, thus, ADCC. Clinical data in abstract form suggest activity similar to that of rituximab.

GA-101 is a novel type II anti-CD20 antibody with an Fc region which has been engineered to increase its affinity for $\mathrm{Fc}$ receptors on immune effector cells. GA-101 shows superior activity to rituximab in preclinical models of ADCC and B-cell depletion [98]. Because GA-101 is a type II antibody, it has been proposed that it may be effective even in rituximab-resistant patients. Clinical experience thus far is limited, but preliminary results of a Phase I/II trial showed an overall response rate of 58\% in patients who had previously received rituximab [99]. However, these patients were not necessarily rituximab-refractory, and the final results of the study await publication.

Thus, numerous novel anti-CD20 monoclonal antibodies have been produced. In many cases, these new molecules have been modified to address mechanisms of rituximab resistance. Several have been tested in clinical trials, and are capable of inducing objective tumor responses in a proportion of follicular NHL patients with prior rituximab exposure. However, only ofatumumab has been explicitly tested in rituximab-resistant patients. Its efficacy in that population was disappointing. Thus, while structural modification and novel antibody production hold the theoretical promise of overcoming rituximab resistance, this 
promise has yet to be demonstrated clinically. Clinical trials of GA-101 appear promising, and mature results from these trials are eagerly awaited.

\section{RECOMMENDATIONS FOR THE CLINICIAN}

The proliferation of varied (and sometimes contradictory) preclinical results and the lack of high-quality clinical data create a difficult situation for the clinician faced with a patient with rituximab-resistant follicular NHL. Treatment and maintenance therapy should be driven by clinical trial results wherever possible. There are no data at present indicating that changing rituximab dose or schedule to overcome resistance in follicular NHL is effective, although clinical trials addressing this question are needed. Similarly, there are no compelling data showing that maintenance is more effective than retreatment with rituximab at disease progression in follicular NHL, although an ongoing ECOG trial is addressing this question. At this point, the primary recommendation for clinicians is the enrollment of patients with rituximab-resistant follicular NHL onto well-designed clinical trials wherever possible. Outside of the clinical trial setting, a number of approaches are reasonable, and there are few data to guide the approach to patients with rituximab-resistant disease.

\section{SUMMARY}

Rituximab is currently the most effective and widely used therapeutic monoclonal antibody in clinical medicine. Rituximab resistance is a common clinical occurrence, present in approximately half of treatment-naïve patients and developing with repeated treatment in the remainder. Nonetheless, there is surprisingly little knowledge of how to approach and circumvent rituximab resistance. Both the mechanisms of resistance and the mechanisms of action of rituximab remain incompletely defined. Variations in B-cell lines, animal model systems, and techniques used to generate rituximab-resistant clones contribute to the complexity of synthesizing preclinical results. The lack of pharmacokinetic-driven clinical trials and the heterogeneity of patients with NHL and CLL further complicate the understanding of these mechanisms in vivo.

Despite these limitations, a number of promising approaches have been explored to enhance the effectiveness of rituximab and to overcome rituximab resistance. Combinations of rituximab with agents designed to enhance CD20 expression, augment complement activity, or increase susceptibility to apoptosis are likewise of great interest. Finally, the impact of rituximab dosing on overcoming rituximab resistance remains to be defined. Ultimately, as rituximab works through multiple mechanisms, it is likely that multiple approaches may be necessary to overcome resistance. The lessons learned from rituximab will hopefully provide a basis for tackling questions of resistance to future antibody-based cancer therapies.

\section{Acknowledgments}

Supported by grants CA76930, CA18029, and CA78902 from the National Institutes of Health, Bethesda, Maryland, USA. The funding sources had no role in the conception, preparation, or approval of this manuscript.

\section{REFERENCES}

1. Khouri IF, Saliba RM, Hosing C, et al. Concurrent administration of high-dose rituximab before and after autologous stem-cell transplantation for relapsed aggressive B-cell non-Hodgkin's lymphomas. J Clin Oncol. 2005; 23:2240-2247. [PubMed: 15800314]

2. Neumann F, Harmsen S, Martin S, et al. Rituximab long-term maintenance therapy after autologous stem cell transplantation in patients with B-cell non-Hodgkin's lymphoma. Ann Hematol. 2006; 85:530-534. [PubMed: 16639571] 
3. Khouri IF, McLaughlin P, Saliba RM, et al. Eight-year experience with allogeneic stem cell transplantation for relapsed follicular lymphoma after nonmyeloablative conditioning with fludarabine, cyclophosphamide, and rituximab. Blood. 2008; 111:5530-5536. [PubMed: 18411419]

4. Reff ME, Carner K, Chambers KS, et al. Depletion of B cells in vivo by a chimeric mouse human monoclonal antibody to CD20. Blood. 1994; 83:435-445. [PubMed: 7506951]

5. Hultin LE, Hausner MA, Hultin PM, Giorgi JV. CD20 (pan-B cell) antigen is expressed at a low level on a subpopulation of human T lymphocytes. Cytometry. 1993; 14:196-204. [PubMed: 7679964]

6. Warzynski MJ, Graham DM, Axtell RA, et al. Low level CD20 expression on T cell malignancies. Cytometry. 1994; 18:88-92. [PubMed: 7523045]

7. Anderson KC, Bates MP, Slaughenhoupt BL, et al. Expression of human B cell-associated antigens on leukemias and lymphomas: A model of human B cell differentiation. Blood. 1984; 63:14241433. [PubMed: 6609729]

8. Press OW, Appelbaum F, Ledbetter JA, et al. Monoclonal antibody 1F5 (anti-CD20) serotherapy of human B cell lymphomas. Blood. 1987; 69:584-591. [PubMed: 3492224]

9. Li H, Ayer LM, Lytton J, Deans JP. Store-operated cation entry mediated by CD20 in membrane rafts. J Biol Chem. 2003; 278:42427-42434. [PubMed: 12920111]

10. O'Keefe TL, Williams GT, Davies SL, Neuberger MS. Mice carrying a CD20 gene disruption. Immunogenetics. 1998; 48:125-132. [PubMed: 9634476]

11. Deans JP, Robbins SM, Polyak MJ, Savage JA. Rapid redistribution of CD20 to a low density detergent-insoluble membrane compartment. J Biol Chem. 1998; 273:344-348. [PubMed: 9417086]

12. Pike LJ. Rafts defined: a report on the Keystone Symposium on Lipid Rafts and Cell Function. J Lipid Res. 2006; 47:1597-1598. [PubMed: 16645198]

13. Boyd RS, Jukes-Jones R, Walewska R, et al. Protein profiling of plasma membranes defines aberrant signaling pathways in mantle cell lymphoma. Molecular \& Cellular Proteomics. 2009; 8:1501-1515. [PubMed: 19346216]

14. Meyer zum Büschenfelde C, Feuerstacke Y, Götze KS, et al. GM1 expression of non-Hodgkin's lymphoma determines susceptibility to rituximab treatment. Cancer Res. 2008; 68:5414-5422. [PubMed: 18593944]

15. Reff ME, Carner K, Chambers KS, et al. Depletion of B cells in vivo by a chimeric mouse human monoclonal antibody to CD20. Blood. 1994; 83:435-445. [PubMed: 7506951]

16. Flieger D, Renoth S, Beier I, et al. Mechanism of cytotoxicity induced by chimeric mouse human monoclonal antibody IDEC-C2B8 in CD20-expressing lymphoma cell lines. Cell Immunol. 2000; 204:55-63. [PubMed: 11006018]

17. Di Gaetano N, Cittera E, Nota R, et al. Complement activation determines the therapeutic activity of rituximab in vivo. J Immunol. 2003; 171:1581-1587. [PubMed: 12874252]

18. Uchida J, Hamaguchi Y, Oliver JA, et al. The innate mononuclear phagocyte network depletes B lymphocytes through Fc receptor-dependent mechanisms during anti-CD20 antibody immunotherapy. J Exp Med. 2004; 199:1659-1669. [PubMed: 15210744]

19. Kennedy AD, Beum PV, Solga MD, et al. Rituximab infusion promotes rapid complement depletion and acute CD20 loss in chronic lymphocytic leukemia. J Immunol. 2004; 172:32803288. [PubMed: 14978136]

20. Racila E, Link BK, Weng WK, et al. A polymorphism in the complement component C1qA correlates with prolonged response following rituximab therapy of follicular lymphoma. Clin Cancer Res. 2008; 14:6697-6703. [PubMed: 18927313]

21. Bannerji R, Kitada S, Flinn IW, et al. Apoptotic-regulatory and complement-protecting protein expression in chronic lymphocytic leukemia: relationship to in vivo rituximab resistance. J Clin Oncol. 2003; 21:1466-1471. [PubMed: 12697868]

22. Weng WK, Levy R. Expression of complement inhibitors CD46, CD55, and CD59 on tumor cells does not predict clinical outcome after rituximab treatment in follicular non-Hodgkin lymphoma. Blood. 2001; 98:1352-1357. [PubMed: 11520782]

23. van der Kolk LE, Grillo-Lopez AJ, Baars JW, et al. Complement activation plays a key role in the side-effects of rituximab treatment. Br J Haematol. 2001; 115:807-811. [PubMed: 11843813] 
24. Koene HR, Kleijer M, Algra J, et al. Fc gammaRIIIa-158V/F polymorphism influences the binding of IgG by natural killer cell Fc gammaRIIIa, independently of the Fc gammaRIIIa-48L/R/H phenotype. Blood. 1997; 90:1109-1114. [PubMed: 9242542]

25. Kim DH, Jung HD, Kim JG, et al. FCGR3A gene polymorphisms may correlate with response to frontline R-CHOP therapy for diffuse large B-cell lymphoma. Blood. 2006; 108:2720-2725. [PubMed: 16609067]

26. Cartron G, Dacheux L, Salles G, et al. Therapeutic activity of humanized anti-CD20 monoclonal antibody and polymorphism in IgG Fc receptor FcgammaRIIIa gene. Blood. 2002; 99:754-758. [PubMed: 11806974]

27. Weng WK, Levy R. Two immunoglobulin G fragment C receptor polymorphisms independently predict response to rituximab in patients with follicular lymphoma. J Clin Oncol. 2003; 21:39403947. [PubMed: 12975461]

28. Weng WK, Weng WK, Levy R. Immunoglobulin G Fc receptor polymorphisms do not correlate with response to chemotherapy or clinical course in patients with follicular lymphoma. Leuk Lymphoma. 2009; 50:1494-1500. [PubMed: 19672774]

29. Farag SS, Flinn IW, Modali R, et al. Fc gamma RIIIa and Fc gamma RIIa polymorphisms do not predict response to rituximab in B-cell chronic lymphocytic leukemia. Blood. 2004; 103:14721474. [PubMed: 14563637]

30. Hofmeister JK, Cooney D, Coggeshall KM. Clustered CD20 induced apoptosis: src-family kinase, the proximal regulator of tyrosine phosphorylation, calcium influx, and caspase 3-dependent apoptosis. Blood Cells Molecules and Diseases. 2000; 26:133-143.

31. Shan D, Ledbetter JA, Press OW. Apoptosis of malignant human B cells by ligation of CD20 with monoclonal antibodies. Blood. 1998; 91:1644-1652. [PubMed: 9473230]

32. Mathas S, Rickers A, Bommert K, et al. Anti-CD20- and B-cell receptor-mediated apoptosis: evidence for shared intracellular signaling pathways. Cancer Res. 2000; 60:7170-7176. [PubMed: 11156427]

33. Byrd JC, Kitada S, Flinn IW, et al. The mechanism of tumor cell clearance by rituximab in vivo in patients with B-cell chronic lymphocytic leukemia: evidence of caspase activation and apoptosis induction. Blood. 2002; 99:1038-1043. [PubMed: 11807010]

34. Chan HT, Hughes D, French RR, et al. CD20-induced lymphoma cell death is independent of both caspases and its redistribution into triton X-100 insoluble membrane rafts. Cancer Res. 2003; 63:5480-5489. [PubMed: 14500384]

35. van der Kolk LE, Evers LM, Omene C, et al. CD20-induced B cell death can bypass mitochondria and caspase activation. Leukemia. 2002; 16:1735-1744. [PubMed: 12200688]

36. Shan D, Ledbetter JA, Press OW. Signaling events involved in anti-CD20-induced apoptosis of malignant human B cells. Cancer Immunology and Immunotherapy. 2000; 48:673-683. [PubMed: 10752475]

37. Zhao WL, Daneshpouy ME, Mounier N, et al. Prognostic significance of bcl-xL gene expression and apoptotic cell counts in follicular lymphoma. Blood. 2004; 103:695-697. [PubMed: 12969962]

38. Mounier N, Briere J, Gisselbrecht C, et al. Rituximab plus CHOP (R-CHOP) overcomes bcl-2-associated resistance to chemotherapy in elderly patients with diffuse large B-cell lymphoma (DLBCL). Blood. 2003; 101:4279-4284. [PubMed: 12576316]

39. Selenko N, Majdic O, Jager U, et al. Cross-priming of cytotoxic T cells promoted by apoptosisinducing tumor cell reactive antibodies? (Review). J Clin Immunol. 2002; 22:124-130. [PubMed: 12078853]

40. Selenko N, Maidic O, Draxier S, et al. CD20 antibody (C2B8)-induced apoptosis of lymphoma cells promotes phagocytosis by dendritic cells and cross-priming of $\mathrm{CD} 8^{+}$cytotoxic T cells. Leukemia. 2001; 15:1619-1626. [PubMed: 11587221]

41. Maloney DG, Grillo-Lopez AJ, White CA, et al. IDEC-C2B8 (Rituximab) anti-CD20 monoclonal antibody therapy in patients with relapsed low-grade non-Hodgkin's lymphoma (Rapid Communication). Blood. 1997; 90:2188-2195. [PubMed: 9310469] 
42. Ghielmini M, Schmitz SF, Cogliatti SB, et al. Prolonged treatment with rituximab in patients with follicular lymphoma significantly increases event-free survival and response duration compared with the standard weekly x 4 schedule. Blood. 2004; 103:4416-4423. [PubMed: 14976046]

43. Davis TA, White CA, Grillo-López AJ, et al. Single-agent monoclonal antibody efficacy in bulky non-Hodgkin's lymphoma: results of a phase II trial of rituximab. J Clin Oncol. 1999; 17:18511857. [PubMed: 10561225]

44. Davis TA, Grillo-López AJ, White CA, et al. Rituximab anti-CD20 monoclonal antibody therapy in non-Hodgkin's lymphoma: safety and efficacy of re-treatment. J Clin Oncol. 2000; 18:31353143. [PubMed: 10963642]

45. Marcus R, Imrie K, Belch A, et al. CVP chemotherapy plus rituximab compared with CVP as firstline treatment for advanced follicular lymphoma. Blood. 2005; 105:1417-1423. [PubMed: 15494430]

46. Hochster H, Weller E, Gascoyne RD, et al. Maintenance rituximab after cyclophosphamide, vincristine, and prednisone prolongs progression-free survival in advanced indolent lymphoma: results of the randomized phase III ECOG1496 Study. J Clin Oncol. 2009; 27:1607-1614. [PubMed: 19255334]

47. Salles GA, Seymour JF, Feugier P, et al. Rituximab maintenance for 2 years in patients with untreated high tumor burden follicular lymphoma after response to immunochemotherapy. J Clin Oncol. 2010; 28(Part 1):574s, 8004.

48. Beers SA, French RR, Chan HT, et al. Antigenic modulation limits the efficacy of anti-CD20 antibodies: implications for antibody selection. Blood. 2010; 115:5191-5201. [PubMed: 20223920]

49. Fishelson Z, Donin N, Zell S, et al. Obstacles to cancer immunotherapy: expression of membrane complement regulatory proteins (mCRPs) in tumors (Review). Mol Immunol. 2003; 40:109-123. [PubMed: 12914817]

50. Takei K, Yamazaki T, Sawada U, et al. Analysis of changes in CD20, CD55, and CD59 expression on established rituximab-resistant B-lymphoma cell lines. Leuk Res. 2006; 30:625-631. [PubMed: 16289746]

51. Golay J, Lazzari M, Facchinetti V, et al. CD20 levels determine the in vitro susceptibility to rituximab and complement of B-cell chronic lymphocytic leukemia: further regulation by CD55 and CD59. Blood. 2001; 98:3383-3389. [PubMed: 11719378]

52. Ziller F, Macor P, Bulla R, et al. Controlling complement resistance in cancer by using human monoclonal antibodies that neutralize complement-regulatory proteins CD55 and CD59. Eur J Immunol. 2005; 35:2175-2183. [PubMed: 15971270]

53. Macor $\mathrm{P}$, Tripodo $\mathrm{C}$, Zorzet $\mathrm{S}$, et al. In vivo targeting of human neutralizing antibodies against CD55 and CD59 to lymphoma cells increases the antitumor activity of rituximab. Cancer Res. 2007; 67:10556-10563. [PubMed: 17975000]

54. Terui Y, Sakurai T, Mishima Y, et al. Blockade of bulky lymphoma-associated CD55 expression by RNA interference overcomes resistance to complement-dependent cytotoxicity with rituximab. Cancer Science. 2006; 97:72-79. [PubMed: 16367924]

55. Di Gaetano N, Xiao Y, Erba E, et al. Synergism between fludarabine and rituximab revealed in a follicular lymphoma cell line resistant to the cytotoxic activity of either drug alone. Br J Haematol. 2001; 114:800-809. [PubMed: 11564066]

56. Klepfish A, Gilles L, Ioannis K, et al. Enhancing the action of rituximab in chronic lymphocytic leukemia by adding fresh frozen plasma: complement/rituximab interactions \& clinical results in refractory CLL. Ann NY Acad Sci. 2009; 1173:865-873. [PubMed: 19758239]

57. Xu W, Miao KR, Zhu DX, et al. Enhancing the action of rituximab by adding fresh frozen plasma for the treatment of fludarabine refractory chronic lymphocytic leukemia. Int J Cancer. 9999 prepublished online July 15, 2010. 10.1002/ijc.25560

58. Winiarska M, Bil J, Wilczek E, et al. Statins impair antitumor effects of rituximab by inducing conformational changes of CD20. PLoS Medicine. 2008; 5:e64. [PubMed: 18366248]

59. Wang SY, Veeramani S, Racila E, et al. Depletion of the C3 component of complement enhances the ability of rituximab-coated target cells to activate human NK cells and improves the efficacy of 
monoclonal antibody therapy in an in vivo model. Blood. 2009; 114:5322-5330. [PubMed: 19805620]

60. Jazirehi AR, Vega MI, Bonavida B. Development of rituximab-resistant lymphoma clones with altered cell signaling and cross-resistance to chemotherapy. Cancer Res. 2007; 67:1270-1281. [PubMed: 17283164]

61. Vega MI, Huerta-Yepez S, Martinez-Paniagua M, et al. Rituximab-mediated cell signaling and chemo/immuno-sensitization of drug-resistant B-NHL is independent of its Fc functions. Clin Cancer Res. 2009; 15:6582-6594. [PubMed: 19861448]

62. Olejniczak SH, Hernandez-Ilizaliturri FJ, Clements JL, Czuczman MS. Acquired resistance to rituximab is associated with chemotherapy resistance resulting from decreased Bax and Bak expression. Clin Cancer Res. 2008; 14:1550-1560. [PubMed: 18316580]

63. Haidar JH, Shamseddine A, Salem Z, et al. Loss of CD20 expression in relapsed lymphomas after rituximab therapy. Eur J Haematol. 2003; 70:330-332. [PubMed: 12694172]

64. Czuczman MS, Olejniczak S, Gowda A, et al. Acquirement of rituximab resistance in lymphoma cell lines is associated with both global CD20 gene and protein down-regulation regulated at the pretranscriptional and posttranscriptional levels. Clin Cancer Res. 2008; 14:1561-1570. [PubMed: 18316581]

65. Terui Y, Mishima Y, Sugimura N, et al. Identification of CD20 C-terminal deletion mutations associated with loss of CD20 expression in non-Hodgkin's lymphoma. Clin Cancer Res. 2009; 15:2523-2530. [PubMed: 19276251]

66. Beum PV, Kennedy AD, Williams ME, et al. The shaving reaction: rituximab/CD20 complexes are removed from mantle cell lymphoma and chronic lymphocytic leukemia cells by THP-1 monocytes. J Immunol. 2006; 176:2600-2609. [PubMed: 16456022]

67. Li Y, Williams ME, Cousar JB, et al. Rituximab-CD20 complexes are shaved from Z138 mantle cell lymphoma cells in intravenous and subcutaneous SCID mouse models. J Immunol. 2007; 179:4263-4271. [PubMed: 17785867]

68. Beum PV, Lindorfer MA, Taylor RP. Within peripheral blood mononuclear cells, antibodydependent cellular cytotoxicity of rituximab-opsonized Daudi cells is promoted by NK cells and inhibited by monocytes due to shaving. J Immunol. 2008; 181:2916-2924. [PubMed: 18684983]

69. Gong Q, Ou Q, Ye S, et al. Importance of cellular microenvironment and circulatory dynamics in B cell immunotherapy. J Immunol. 2005; 174:817-826. [PubMed: 15634903]

70. Khouri IF, Saliba RM, Hosing C, et al. Concurrent administration of high-dose rituximab before and after autologous stem-cell transplantation for relapsed aggressive B-cell non-Hodgkin's lymphomas. J Clin Oncol. 2005; 23:2240-2247. [PubMed: 15800314]

71. Dayde D, Ternant D, Ohresser M, et al. Tumor burden influences exposure and response to rituximab: pharmacokinetic-pharmacodynamic modeling using a syngeneic bioluminescent murine model expressing human CD20. Blood. 2009; 113:3765-3772. [PubMed: 19029438]

72. Ternant D, Henin E, Cartron G, et al. Development of a drug-disease simulation model for rituximab in follicular non-Hodgkin's lymphoma. Br J Clin Pharmacol. 2009; 68:561-573. [PubMed: 19843059]

73. Sugimoto T, Tomita A, Hiraga J, et al. Escape mechanisms from antibody therapy to lymphoma cells: downregulation of CD20 mRNA by recruitment of the HDAC complex and not by DNA methylation. Biochem Biophys Res Commun. 2009; 390:48-53. [PubMed: 19769942]

74. Shimizu R, Kikuchi J, Wada T, et al. HDAC inhibitors augment cytotoxic activity of rituximab by upregulating CD20 expression on lymphoma cells. Leukemia. 9999 prepublished online August 5, 2010. 10.1038/leu.2010.157

75. Wang M, Han XH, Zhang L, et al. Bortezomib is synergistic with rituximab and cyclophosphamide in inducing apoptosis of mantle cell lymphoma cells in vitro and in vivo. Leukemia. 2008; 22:179185. [PubMed: 17898787]

76. Wanner K, Hipp S, Oelsner M, et al. Mammalian target of rapamycin inhibition induces cell cycle arrest in diffuse large B cell lymphoma (DLBCL) cells and sensitises DLBCL cells to rituximab. Br J Haematol. 2006; 134:475-484. [PubMed: 16856892] 
77. de Vos S, Goy A, Dakhil SR, et al. Multicenter randomized phase II study of weekly or twiceweekly bortezomib plus rituximab in patients with relapsed or refractory follicular or marginalzone B-cell lymphoma. J Clin Oncol. 2009; 27:5023-5030. [PubMed: 19770386]

78. Bil J, Winiarska M, Nowis D, et al. Bortezomib modulates surface CD20 in B-cell malignancies and affects rituximab-mediated complement-dependent cytotoxicity. Blood. 2010; 115:3745-3755. [PubMed: 20200358]

79. Pro B, Leber B, Smith M, et al. Phase II multicenter study of oblimersen sodium, a Bcl-2 antisense oligonucleotide, in combination with rituximab in patients with recurrent B-cell non-Hodgkin lymphoma. Br J Haematol. 2008; 143:355-360. [PubMed: 18764869]

80. Hernandez-Ilizaliturri FJ, Jupudy V, Reising S, et al. Concurrent administration of granulocyte colony-stimulating factor or granulocyte-monocyte colony-stimulating factor enhances the biological activity of rituximab in a severe combined immunodeficiency mouse lymphoma model. Leukemia \& Lymphoma. 2005; 46:1775-1784. [PubMed: 16263581]

81. van der Kolk LE, Grillo-Lopez AJ, Baars JW, van Oers MH. Treatment of relapsed B-cell nonHodgkin's lymphoma with a combination of chimeric anti-CD20 monoclonal antibodies (rituximab) and G-CSF: final report on safety and efficacy. Leukemia. 2003; 17:1658-1664. [PubMed: 12886256]

82. Moga E, Alvarez E, Canto E, et al. NK cells stimulated with IL-15 or CpG ODN enhance rituximab-dependent cellular cytotoxicity against B-cell lymphoma. Exp Hematol. 2008; 36:6977. [PubMed: 17959301]

83. Khan KD, Emmanouilides C, Benson DM Jr, et al. A phase 2 study of rituximab in combination with recombinant interleukin-2 for rituximab-refractory indolent non-Hodgkin's lymphoma. Clin Cancer Res. 2006; 12:7046-7053. [PubMed: 17145827]

84. Berdeja JG, Hess A, Lucas DM, et al. Systemic interleukin-2 and adoptive transfer of lymphokineactivated killer cells improves antibody-dependent cellular cytotoxicity in patients with relapsed B-cell lymphoma treated with rituximab. Clin Cancer Res. 2007; 13:2392-2399. [PubMed: 17438098]

85. Friedberg JW, Kelly JL, Neuberg D, et al. Phase II study of a TLR-9 agonist (1018 ISS) with rituximab in patients with relapsed or refractory follicular lymphoma. Br J Haematol. 2009; 146:282-291. [PubMed: 19519691]

86. Gertner-Dardenne J, Bonnafous C, Bezombes C, et al. Bromohydrin pyrophosphate enhances antibody-dependent cell-mediated cytotoxicity induced by therapeutic antibodies. Blood. 2009; 113:4875-4884. [PubMed: 19278954]

87. Friedberg JW, Kim H, McCauley M, et al. Combination immunotherapy with a CpG oligonucleotide (1018 ISS) and rituximab in patients with non-Hodgkin lymphoma: increased interferon-alpha/beta-inducible gene expression, without significant toxicity. Blood. 2005; 105:489-495. [PubMed: 15358617]

88. Teeling JL, French RR, Cragg MS, et al. Characterization of new human CD20 monoclonal antibodies with potent cytolytic activity against non-Hodgkin lymphomas. Blood. 2004; 104:1793-1800. [PubMed: 15172969]

89. Li B, Shi S, Qian W, et al. Development of novel tetravalent anti-CD20 antibodies with potent antitumor activity. Cancer Res. 2008; 68:2400-2408. [PubMed: 18381448]

90. Craigen JL, Mackus WJM, Engleberts P, et al. Ofatumumab, a human Mab targeting a membraneproximal small-loop epitope on CD20, induces potent NK cell-mediated ADCC. Blood. 2010; 114:687, 1725.

91. Hagenbeek A, Gadeberg O, Johnson P, et al. First clinical use of ofatumumab, a novel fully human anti-CD20 monoclonal antibody in relapsed or refractory follicular lymphoma: results of a phase 1/2 trial. Blood. 2008; 111:5486-5495. [PubMed: 18390837]

92. Hagenbeek A, Fayad L, Delwail V, et al. Evaluation of ofatumumab, a novel human CD20 monoclonal antibody, as single agent therapy in rituximab-refractory follicular lymphoma. Blood. 2010; 114:385-386. 935.

93. Wierda G, Kipps T, Mayer J, et al. High activity of single-agent ofatumumab, a novel CD-20 monoclonal antibody, in fludarabine- and alemtuzumab-refractory or bulky fludarabine-refractory 
chronic lymphocytic leukemia, regardless of prior rituximab exposure. Haematologica. 2009; 94(Suppl 2):369, 0919.

94. Genovese MC, Kaine JL, Lowenstein MB, et al. Ocrelizumab, a humanized anti-CD20 monoclonal antibody, in the treatment of patients with rheumatoid arthritis: a phase I/II randomized, blinded, placebo-controlled, dose-ranging study. Arthritis Rheum. 2008; 58:2652-2661. [PubMed: 18759293]

95. Morschhauser F, Marlton P, Vitolo U, et al. Results of a phase I/II study of ocrelizumab, a fully humanized anti-CD20 mAb, in patients with relapsed/refractory follicular lymphoma. Ann Oncol. 2010; 21:1870-1876. [PubMed: 20157180]

96. Goldenberg DM, Rossi EA, Stein R, et al. Properties and structure-function relationships of veltuzumab (hA20), a humanized anti-CD20 monoclonal antibody [Erratum appears in Blood. 2009 May 21;113(21):5368]. Blood. 2009; 113:1062-1070. [PubMed: 18941114]

97. Morschhauser F, Leonard JP, Fayad L, et al. Humanized anti-CD20 antibody, veltuzumab, in refractory/recurrent non-Hodgkin's lymphoma: phase I/II results. J Clin Oncol. 2009; 27:33463353. [PubMed: 19451441]

98. Mossner E, Brunker P, Moser S, et al. Increasing the efficacy of CD20 antibody therapy through the engineering of a new type II anti-CD20 antibody with enhanced direct and immune effector cell-mediated B-cell cytotoxicity. Blood. 2010; 115:4393-4402. [PubMed: 20194898]

99. Salles GA, Morschhauser F, Cartron G, et al. A phase I/II study of RO5072759 (GA101) in patients with relapsed/refractory CD20+ malignant disease. Blood. 2008; 112:93, 234.

100. Cartron G, Dacheux L, Salles G, et al. Therapeutic activity of humanized anti-CD20 monoclonal antibody and polymorphism in IgG Fc receptor FcgammaRIIIa gene. Blood. 2002; 99:754-758. [PubMed: 11806974]

101. Weng WK, Levy R. Two immunoglobulin G fragment C receptor polymorphisms independently predict response to rituximab in patients with follicular lymphoma. J Clin Oncol. 2003; 21:3940 3947. [PubMed: 12975461]

102. Treon SP, Hansen M, Branagan AR, et al. Polymorphisms in Fc $\gamma$ RIIIA (CD16) receptor expression are associated with clinical response to rituximab in Waldenström's macroglobulinemia. J Clin Oncol. 2005; 23:474-481. [PubMed: 15659493]

103. Kim DH, Jung HD, Kim JG, et al. FCGR3A gene polymorphisms may correlate with response to frontline R-CHOP therapy for diffuse large B-cell lymphoma. Blood. 2006; 108:2720-2725. [PubMed: 16609067]

104. Mitrovic Z, Aurer I, Radman I, et al. FCgammaRIIIA and FCgammaRIIA polymorphisms are not associated with response to rituximab and CHOP in patients with diffuse large B-cell lymphoma. Haematologica. 2007; 92:998-999. [PubMed: 17606457]

105. Galimberti S, Palumbo GA, Caracciolo F, et al. The efficacy of rituximab plus Hyper-CVAD regimen in mantle cell lymphoma is independent of FCgammaRIIIa and FCgammaRIIa polymorphisms. Journal of Chemotherapy. 2007; 19:315-321. [PubMed: 17594928]

106. Carlotti E, Palumbo GA, Oldani E, et al. FcgammaRIIIA and FcgammaRIIA polymorphisms do not predict clinical outcome of follicular non-Hodgkin's lymphoma patients treated with sequential CHOP and rituximab. Haematologica. 2007; 92:1127-1130. [PubMed: 17650444]

107. Dornan D, Spleiss O, Yeh R-F, et al. Effect of FCGR2A and FCGR3A variants on CLL outcome. Blood. 9999 prepublished online August 12, 2010. 10.1182/blood-2010-03-272765 


\section{Table 1}

Published studies of impact of Fc receptor polymorphisms on clinical outcomes of rituximab-treated patients.

\begin{tabular}{|l|l|l|l|}
\hline Paper & Disease & Treatment & Findings \\
\hline Cartron 2002 [100] & Follicular NHL & Rituximab & $\begin{array}{l}\text { Response rate 100\% (V/V) vs. 67\% (V/F or F/F), p=0.03; } \\
\text { responses persisted longer in 158V/V pts as well }\end{array}$ \\
\hline Weng 2003 [101] & Follicular NHL & Rituximab & Better 2-year PFS with 158V/V vs. F carriers (45\% vs. 14\%) \\
\hline Farag 2004 [29] & CLL & Rituximab & $\begin{array}{l}\text { No significant effect of polymorphisms at position 158 on } \\
\text { response rate }\end{array}$ \\
\hline Treon 2005 [102] & Waldenstrom macroglobulinemia & Rituximab & $\begin{array}{l}\text { Better response rate with 158V/V or V/F compared to 158F/F } \\
\text { (36\% vs. 9\%, p=0.03) }\end{array}$ \\
\hline Kim 2006 [103] & DLBCL & R-CHOP & $\begin{array}{l}\text { Higher CR rate with 158V/V vs. 158V/F vs. 158 F/F }(88 \% \\
\text { vs. 49\% vs. 50\%, p=0.002) }\end{array}$ \\
\hline Mitrovic 2007 [104] & DLBCL & R-CHOP & No significant effect of polymorphisms on response rate \\
\hline Galimberti 2007 [105] & Mantle cell lymphoma & R-hyperCVAD & Fc receptor polymorphisms did not influence PFS \\
\hline Carlotti 2006 [106] & Follicular NHL & R-CHOP & $\begin{array}{l}\text { No correlation between Fc receptor polymorphisms and } \\
\text { response rate or survival }\end{array}$ \\
\hline Dornan 2010 [107] & CLL & FCR & FCGR2A and FCGR3A polymorphisms did not affect PFS \\
\hline
\end{tabular}

Abbreviations: NHL, non-Hodgkin lymphoma; PFS, progression-free survival; CLL, chronic lymphocytic leukemia; DLBCL, diffuse large B-cell lymphoma; $\mathrm{CR}$, complete response. 